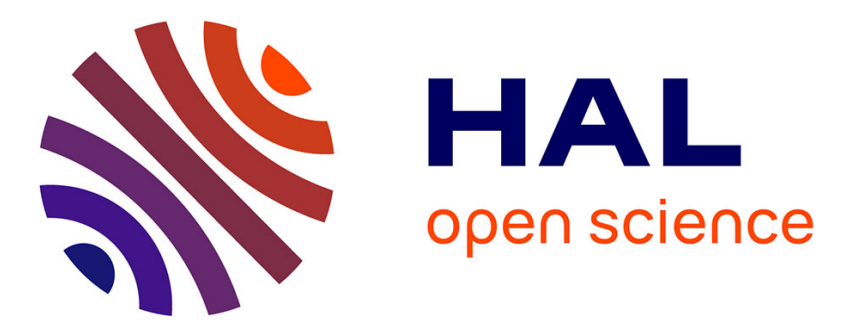

\title{
Etude comparative de l'activité coagulante et du pouvoir protéolytique de la présure animale et de trois de ses succédanés
}

\author{
G. Houins, Cl. Deroanne, R. Coppens
}

\section{- To cite this version:}

G. Houins, Cl. Deroanne, R. Coppens. Etude comparative de l'activité coagulante et du pouvoir protéolytique de la présure animale et de trois de ses succédanés. Le Lait, 1973, 53 (529_530), pp.610-624. hal-00928637

\section{HAL Id: hal-00928637 \\ https://hal.science/hal-00928637}

Submitted on 1 Jan 1973

HAL is a multi-disciplinary open access archive for the deposit and dissemination of scientific research documents, whether they are published or not. The documents may come from teaching and research institutions in France or abroad, or from public or private research centers.
L'archive ouverte pluridisciplinaire HAL, est destinée au dépôt et à la diffusion de documents scientifiques de niveau recherche, publiés ou non, émanant des établissements d'enseignement et de recherche français ou étrangers, des laboratoires publics ou privés. 


\title{
Etude comparative de l'activité coagulante et du pouvoir protéolytique de la présure animale et de trois de ses succédanés
}

\author{
par \\ HOUINS G., DEROANNE Cl. et COPPENS R. \\ Chaire de Technologie Agricole et Alimentaire \\ Faculté des Sciences agronomiques de l'Etat, Gembloux (Belgique)
}

\section{I. - INTRODUCTION}

La pénurie mondiale de présure animale suscite, depuis plusieurs années, des travaux de recherche sur les enzymes coagulants susceptibles d'être utilisés en fromagerie. L'industrie est à présent capable de produire, en quantité pratiquement illimitée, ces succédanés à des prix concurrentiels, et la fabrication à partir de ces enzymes de différents types de fromages est déjà réalisée avec plus ou moins de succès.

De l'ensemble des publications consultées, il ressort que les recherches menées sur les succédanés d'origine fongique sont, jusqu'à présent, les plus fructueuses. Certains chercheurs n'ont trouvé pratiquement aucune différence entre le fromage fabriqué à partir d'enzymes coagulants fongiques et celui caillé par la présure de veau $[4,5,8,12,13]$; cependant, d'autres expérimentateurs ont remarqué chez les premiers le développement d'une amertume plus ou moins marquée $[6,10,16,18]$. Ces défauts sont souvent attribués à une protéolyse excessive, consécutive à un excès du succédané de la présure animale [15].

Dans cet article, nous étudions l'influence des facteurs affectant la coagulation (teneur $\mathrm{Ca}^{++}$, température, $\mathrm{pH}$ ) et l'évolution de la protéolyse du caillé pendant les $5 \mathrm{j}$ qui suivent l'ajoute de la présure animale ou une des trois présures obtenues respectivement à partir d'Endothia parasitica, de Mucor pusillus et de Mucor miehei.

\section{II. - EXPERIMENTATION}

\section{II.1. Matériel}

\section{II.1.1. Les Présures}

La présure animale utilisée est une présure solide. Les succédanés sont des préparations déjà commercialisées, vendues sous forme de 
poudre ou de liquide. La présure "Suparen " est extraite d'Endothia parasitica (E.P.), la "Rennilase » de Mucor miehei (M.M.) et « l' Emporase » de Mucor pusillus (M.P.). Toutes les enzymes ont été diluées dans l'eau distillée.

\section{II.1.2. Le substrat}

Afin d'éviter toute action protéolytique d'origine microbienne, le substrat, constitué d'une solution à 8 p. 100 de poudre de lait écrémé, est additionné de 0,05 p. 100 de chloramphénicol et de 0,04 p. 100 de streptomycine. Mis à part l'essai étudiant l'influence de la concentration en $\mathrm{Ca}^{++}$, la solution est à une concentration 0,01 molaire en $\mathrm{CaCl}_{2}$.

\section{II.2. Méthodes}

\section{II.2.1. Mesure de l'activité coagulante}

La mesure du temps de coagulation est effectuée sur $10 \mathrm{ml}$ de substrat emprésuré placé dans un tube à essai soumis à une rotation de 6 à $8 \mathrm{t} / \mathrm{mn}$ et maintenu dans un bain-marie à la température de $35^{\circ} \mathrm{C}$. Le chronomètre est arrêté dès l'apparition des premiers flocons sur la paroi du tube. La concentration de l'enzyme testée est telle que la coagulation de $10 \mathrm{ml}$ de substrat à la température de $35^{\circ} \mathrm{C}$ a lieu après environ $120 \mathrm{~s}$.

\section{II.2.2. Mesure du pouvoir protéolytique}

\section{II.2.2.1. Détermination de l'accroissement de N.P.N.}

Comme l'ont montré Alais et Lenoir [1,9], l'action protéolytique sur la caséine est caractérisée par la mesure de l'accroissement de l'azote non-protéique (NPN). Cette activité protéolytique a été suivie, par dosage selon Kjeldahl des différentes formes d'azote fractionnées à partir du substrat emprésuré. Les concentrations en présure sont telles que $1 \mathrm{ml}$ de solution enzymatique coagule à $35^{\circ} \mathrm{C} 100 \mathrm{ml}$ de substrat après $8 \mathrm{mn}$.

On dose de la sorte :

$\mathrm{N}$ total (N.T.)

$\mathrm{N}$ soluble (N. Sol.)

N non-protéique (N.P.N.): sur la partie non-précipitée par l'acide trichloracétique (TCA) aux concentrations de 12 p. 100,6 p. 100,2 p. 100.

$\mathrm{N}$ formol (N.F.)
: directement sur le substrat.

: sur le filtrat obtenu après précipitation de la caséine à $\mathrm{pH}$ 4,6 par l'acide chlorhydrique.
: par filtration selon Sörensen sur le filtrat chlorhydrique.

\section{II.2.2.2. Caractérisation de l'action protéolytique}

Nous étudions les peptides produits après $5 \mathrm{~h}$ et $5 \mathrm{j}$ d'emprésurage. Pour extraire ces peptides, le substrat à analyser est agité vigoureusement en présence de 2 p. 100 de TCA et il est ensuite 
placé au repos $10 \mathrm{mn}$, puis il est centrifugé à $1200 \mathrm{t} / \mathrm{mn}$ pendant $5 \mathrm{mn}$. Le filtrat est récupéré et le TCA est extrait par l'éther diéthylique. L'échantillon est alors neutralisé et concentré sous pression réduite. Après $15 \mathrm{mn}$ de centrifugation à $30000 \mathrm{~g}$ dans une enceinte réfrigérée, $6 \mathrm{ml}$ de surnageant sont déposés pour la chromatographie sur une colonne de $2,5 \times 40 \mathrm{~cm}$ de Sephadex $\mathrm{G}_{10}$. L'élution se fait à l'eau additionnée de 0,02 p. 100 de $\mathrm{NaN}_{3}$ comme antiseptique, à la vitesse moyenne de $1 \mathrm{ml} / \mathrm{mn}$. Les fractions chromatographiées sont détectées en continu à 254 mu (LKB Uvicord I) et elles sont recueillies par portions de $5 \mathrm{ml}$.

\section{III. - RESULTAT ET DISCUSSION}

\section{III.1. Facteurs affectant la coagulation}

III.1.1. Influence de la teneur en calcium soluble

La vitesse de coagulation est suivie à la température de $35^{\circ} \mathrm{C}$, sur le substrat décrit précédemment additionné de doses croissantes de $\mathrm{CaCl}_{2}$. Les concentrations en enzymes sont telles, que la coagulation de $10 \mathrm{ml}$ de substrat 0,01 molaire en $\mathrm{CaCl}_{2}$ se produit après environ 120 s. Nous constatons (fig. 1) que les présures d'origines fongiques

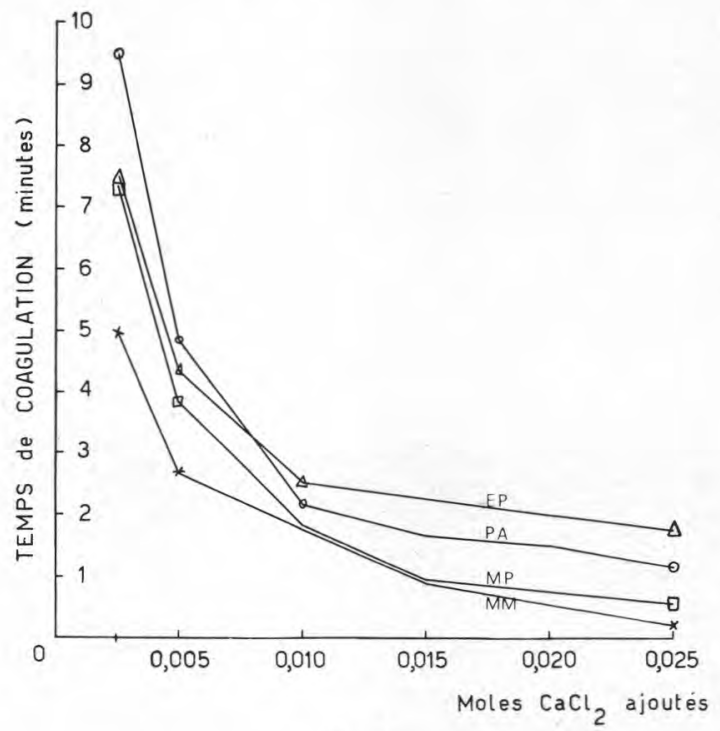

fig. 1

Influence du calcium sur le temps de coagulation par quatre enzymes : présure animale (P.A.), Mucor pusillus (M.P.), Mucor miehei (M.M.), Endothia parasitica (E.P.). 
sont moins sensibles aux ions calcium que la présure animale lorsque les quantités de $\mathrm{CaCl}_{2}$ ajoutées ne dépassent pas 0,008 moles ; celle provenant de Mucor miehei est particulièrement peu sensible, alors que les deux autres ont pratiquement la même sensibilité. Pour des concentrations plus élevées que 0,010 moles, les coefficients de pente $\frac{\mathrm{dtc}}{\mathrm{d} \mathrm{C}_{\mathrm{eaI}}}$ sont sensiblement les mêmes pour, d'une part la présure animale et d'Endothia parasitica, et d'autre part de Mucor pusillus et de Mucor miehei ; ces deux dernières présures montrent une sensibilité légèrement plus grande que les deux premières.

\section{III.1.2. Influence de la température}

Les essais se font sur le substrat standard $(0,01 \mathrm{~mol} \mathrm{CaCl})$ emprésuré dans les conditions précitées.

La figure 2 montre l'analogie remarquable dans le comportement d'Endothia parasitica et de la présure animale avec un maximum d'activité coagulante à $45^{\circ} \mathrm{C}$. Les deux autres présures ont aussi entre elles une similitude de comportement avec un maximum d'activité coagulante à une température élevée : $65^{\circ} \mathrm{C}$, d'ailleurs proche de la température d'inhibition thermique.

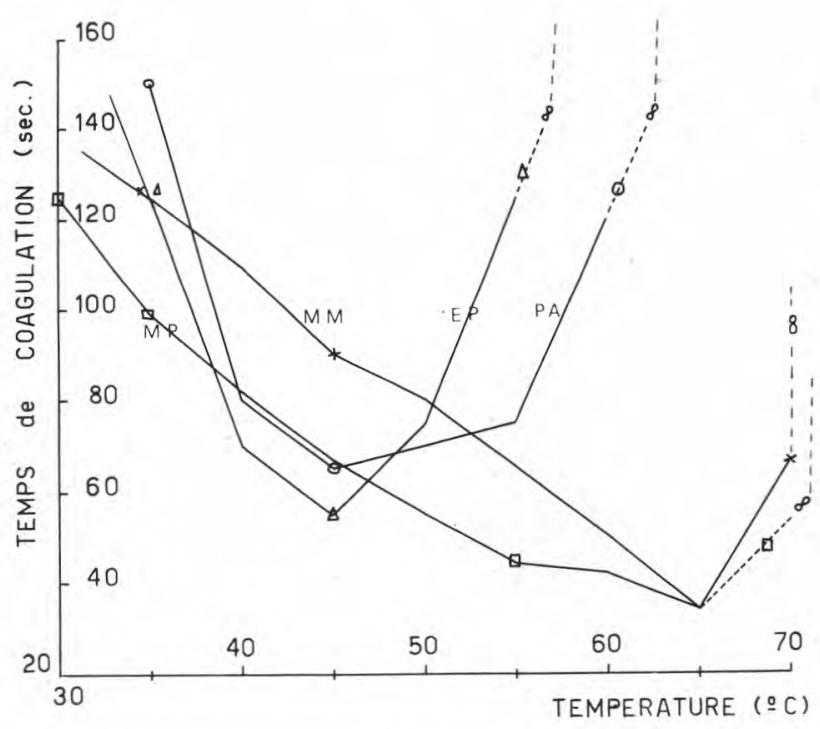

fig. 2

Influence de la température sur le temps de coagulation par quatre enzymes : présure animale (P.A.), Mucor pusillus (M.P.), Mucor miehei (M.M.), Endothia parasitica (E.P.). 


\section{III.1.3. Influence $d u p H$}

L'échelle de $\mathrm{pH}$ est obtenue par addition de $\mathrm{NaOH} 0,1 \mathrm{~N}$. On peut observer (fig. 3) une concordance remarquable du comportement des enzymes de Mucor miehei, d'Endothia parasitica et de la présure animale alors que celle de Mucor pusillus indique une sensibilité nulle entre $\mathrm{pH} \mathrm{5,3} \mathrm{et} \mathrm{pH} 6$, maintenant une activité coagulante élevée qui se ralentit entre $\mathrm{pH} 6$ et $\mathrm{pH}$ 6,3 de façon beaucoup moins forte que pour les trois autres présures.

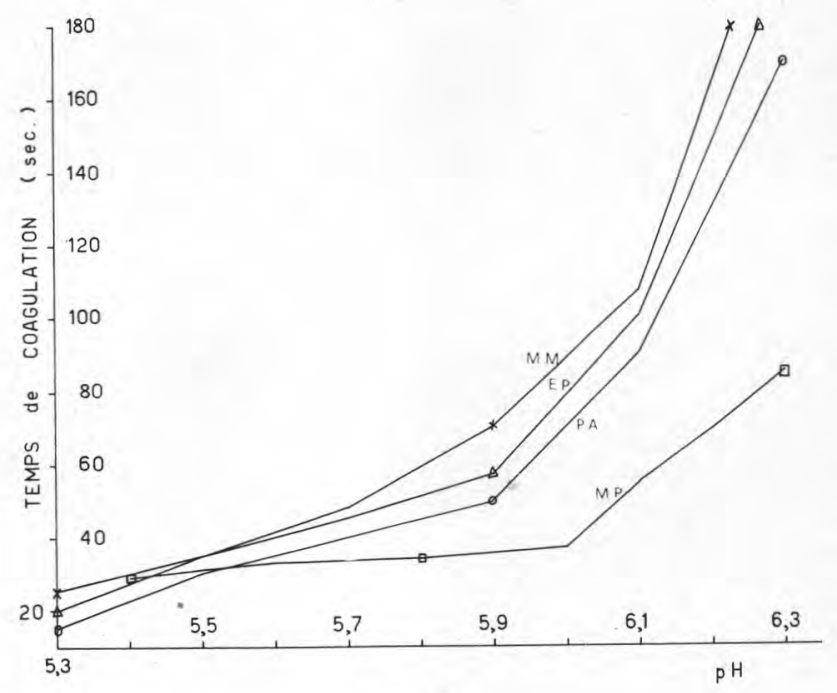

fig. 3

Influence $\mathrm{du} \mathrm{pH}$ sur le temps de coagulation par quatre enzymes : présure animale (P.A.), Mucor pusillus (M.P.), Mucor miehei (M.M.), Endothia parasitica (E.P.).

\section{III.2. Evolution de la protéolyse}

\section{III.2.1. Dosage des différentes formes d'azote}

Afin de caractériser les actions protéolytiques des différents types d'enzymes étudiés, nous avons classé les produits de la protéolyse suivant leur solubilité vis-à-vis de différentes concentrations d'acide trichloracétique. Le dosage de l'azote dans les différentes fractions obtenues permet de faire le classement empirique suivant :

N albuminoïde - peptone* ${ }^{*}$ N.Sol. - N.P.N. (TCA 2 p. 100).

$\mathrm{N}$ peptide*

$\mathrm{N}$ formol

$=$ N.P.N. - N.F.

$=$ N.F.

* Remarque : D'autres classes de peptides peuvent être différenciées puisque les quantités de N.P.N. dosées varient avec les concentrations d'acide trichloracétique ajoutées ( 2 p. 100, 6 p. 100, 12 p. 100). 


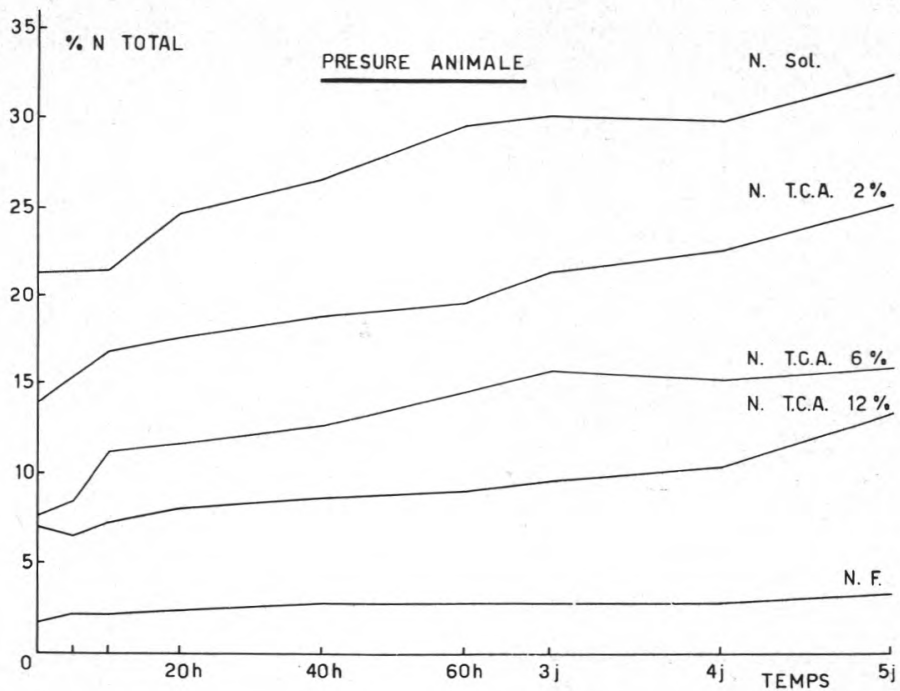

fig. 4

Evolution, exprimée en pourcentage de l'azote total, de la protéolyse de la présure animale pendant $5 \mathrm{j}$.

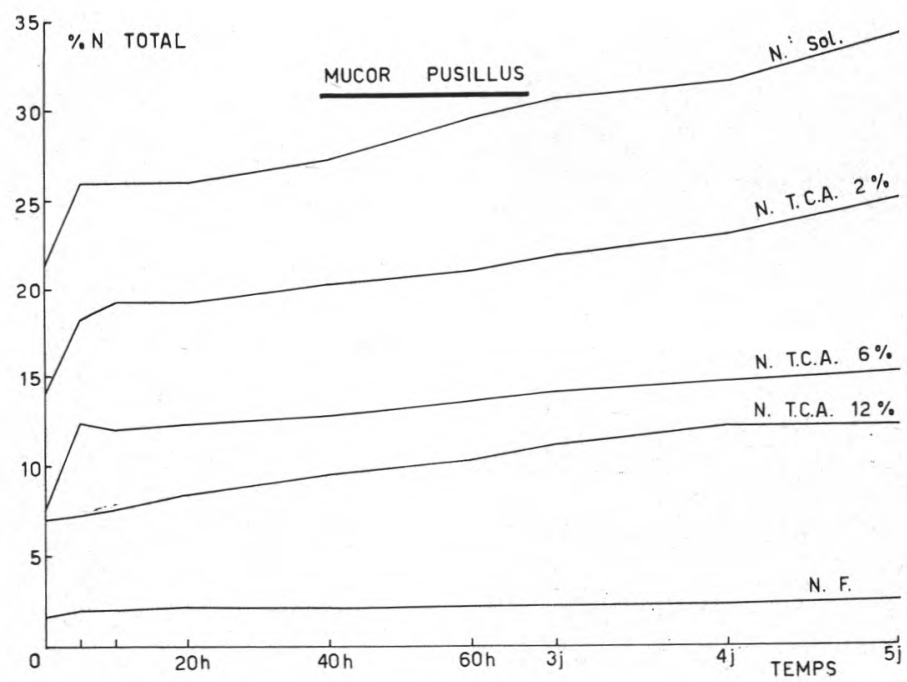

fig. 5

Evolution, exprimée en pourcentage de l'azote total, de la protéolyse de Mucor pusillus pendant $5 \mathrm{j}$. 


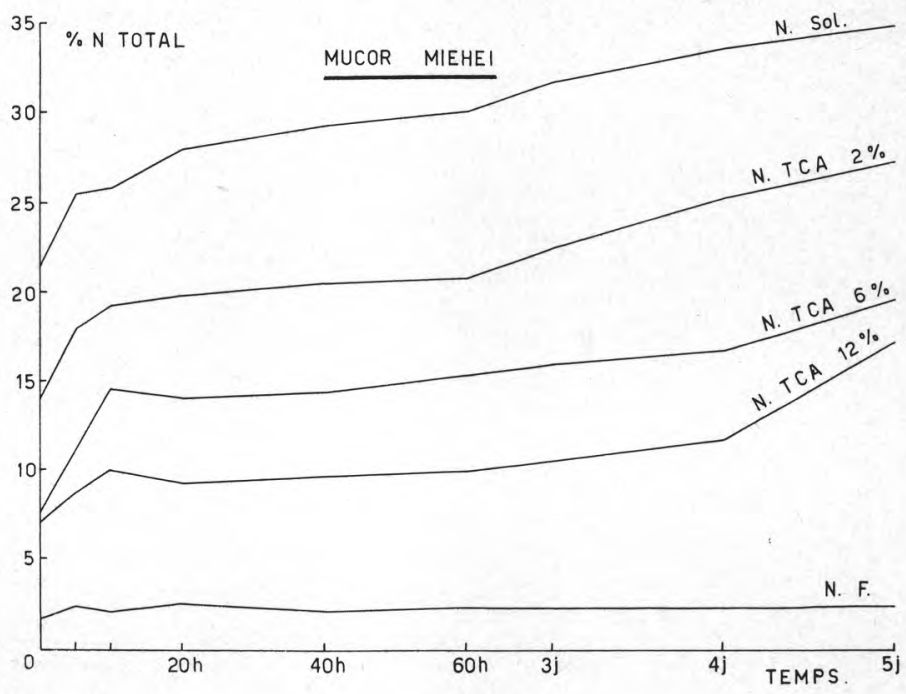

fig. 6

Evolution, exprimée en pourcentage de l'azote total, de la protéolyse de Mucor miehei pendant $5 \mathrm{j}$.

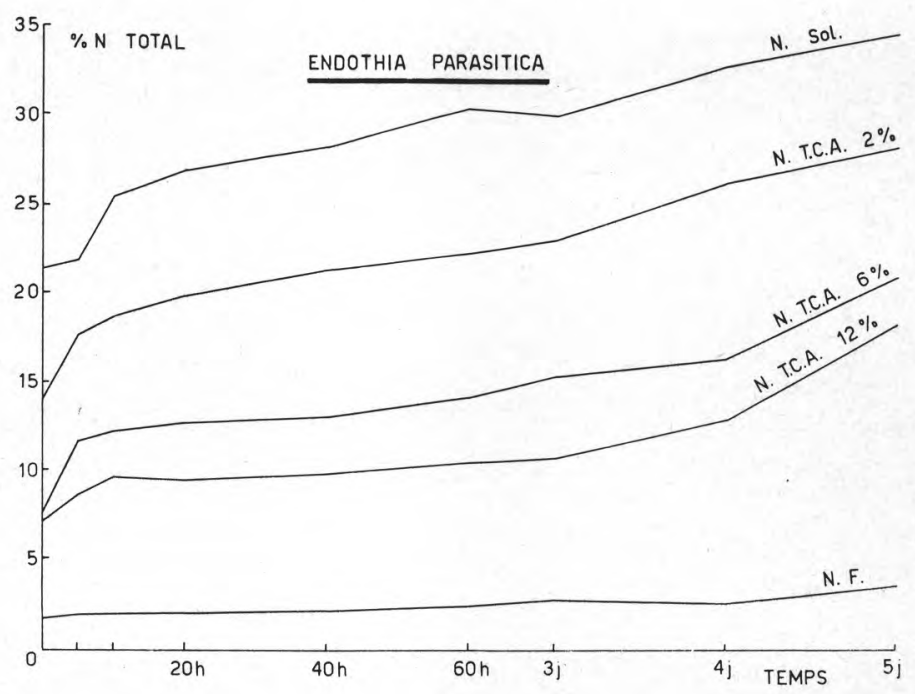

fig. 7

Evolution, exprimée en pourcentage de l'azote total, de la protéolyse d'Endothia parasitica pendant $5 \mathrm{j}$. 


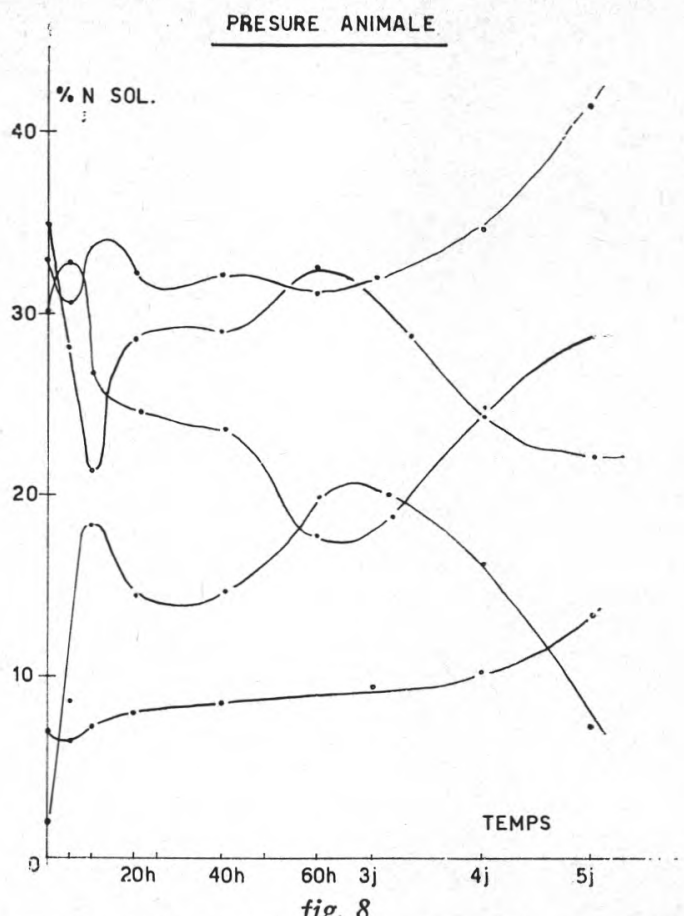

Pourcentage par rapport à l'azote soluble, des différentes formes d'azote non-protéinique dues à la protéolyse de la présure animale.

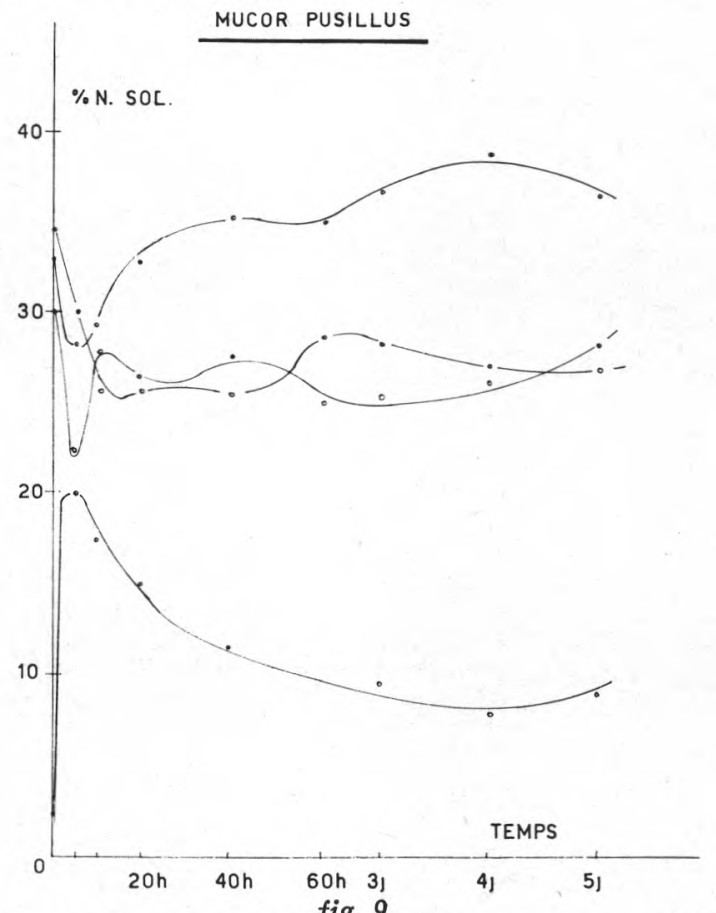

fig. 9

Pourcentage par rapport à l'azote soluble, des différentes formes d'azote non-protéinique dues à la protéolyse de Mucor pusillus. 


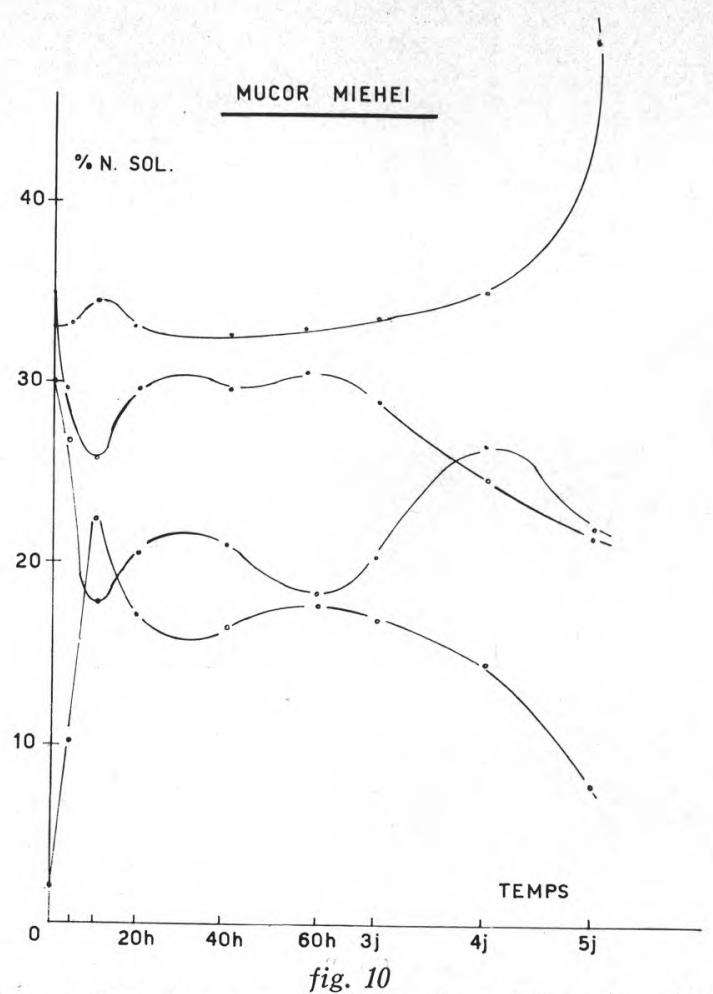

Pourcentage par rapport à l'azote soluble, des différentes formes d'azote non-protéinique dues à la protéolyse de Mucor miehei.

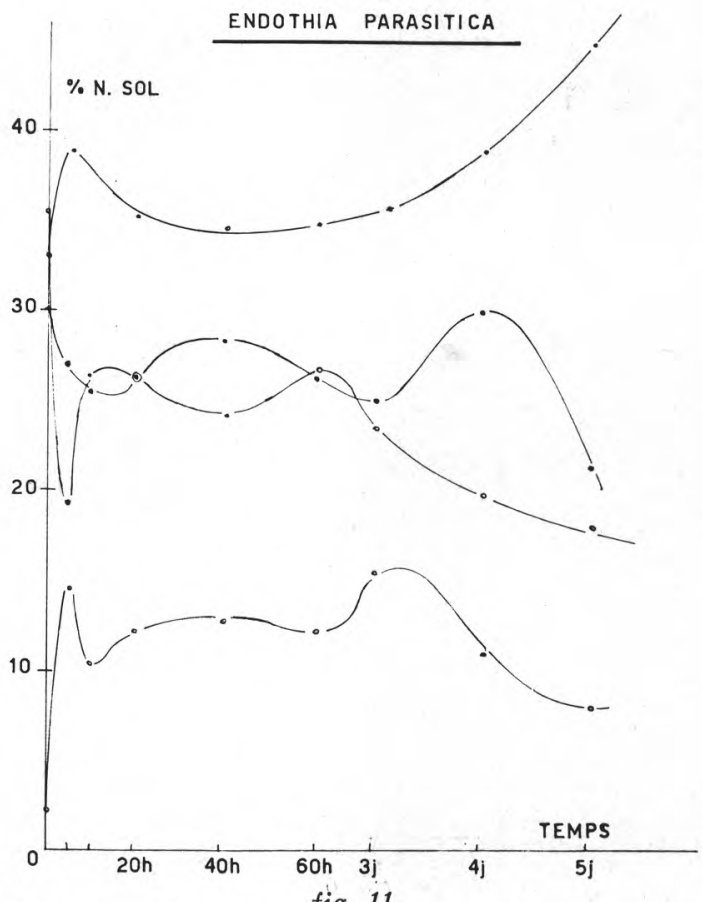

fig. 11

Pourcentage par rapport à l'azote soluble, des différentes formes d'azote non-protéinique dues à la protéolyse d'Endothia parasitica. 
Sur les figures représentant l'évolution des pourcentages par rapport à N.T. (fig. 4, 5, 6, 7) et les proportions par rapport à l'N.Sol. (fig. 8, 9, 10, 11) des différentes formes d'azote, il est possible de distinguer trois périodes :
A. les 10 premières heures d'emprésurage.
B. de $10 \mathrm{~h}$ à $2 \mathrm{j}$ d'emprésurage.
C. de $2 \mathrm{j}$ à $5 \mathrm{j}$ d'emprésurage.

Pendant les 10 premières heures d'action, les succédanés de la présure animale développent rapidement une production importante de N.P.N. (fig. 4) et la quantité relative de petits peptides (N.TCA 6 p. 100 - N.TCA 12 p. 100) (fig. 8) augmente brusquement aux dépens des polypeptides. Toutefois les proportions des différents types d'azote non-protéique évoluent spécifiquement pour chaque enzyme.

La deuxième période, de $10 \mathrm{~h}$ à $2 \mathrm{j}$, se caractérise par une vitesse constante de la protéolyse.

Après $48 \mathrm{~h}$, des variations dans les vitesses d'hydrolyse apparaissent au niveau des différentes formes d'azote, ce qui implique probablement un système complexe d'enzymes protéolytiques. Pendant ce temps, la proportion des très petits peptides et des acides aminés (N.TCA 12 p. 100) progresse rapidement en présence des présures "Suparen " et "Rennilase " (fig. 6, 7). Il faut toutefois remarquer que la présure extraite de Mucor pusillus (Emporase) se distingue des autres enzymes par une protéolyse plus régulière et par l'accumulation de toutes les classes de peptides (fig. 5, 9).

La saveur amère décelée dans certains fromages fabriqués avec la présure animale est due suivant Stadhouders [14] à l'accumulation de certains types de peptides ; cette remarque est également valable pour les présures d'origine fongique et particulièrement pour l'Emporase et la Suparen qui maintiennent une proportion élevée de polypeptides (N.Sol. - N.TCA 2 p. 100) et de gros peptides (N.TCA 2 p. 100 - N.TCA 6 p. 100) (fig. 5, 7, 9, 11) pendant la deuxième période.

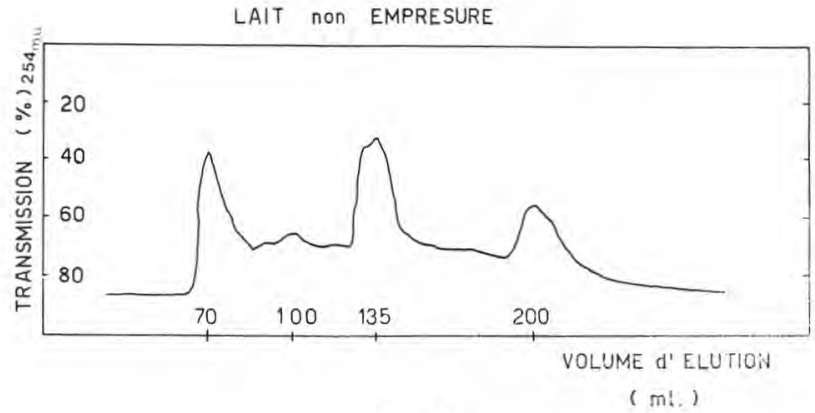

fig. 12

Chromatographie sur colonne de Séphadex $\mathrm{G}_{10}$ de l'extrait par 2 p. 100 de TCA du lait non-emprésuré. 


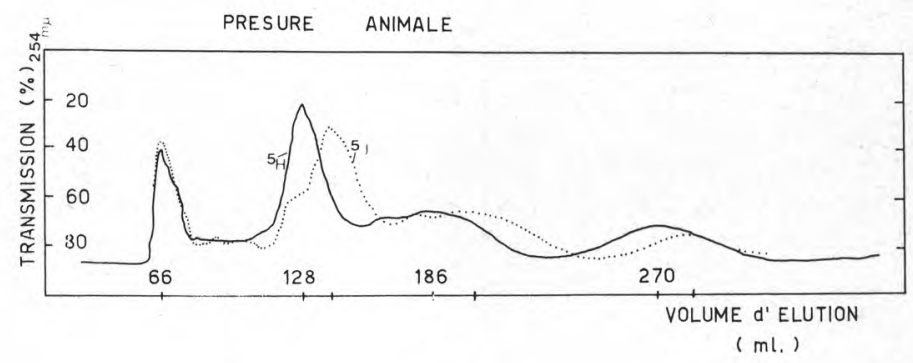

fig. 13

Chromatographie sur colonne de Séphadex $\mathrm{G}_{10}$ de l'extrait par 2 p. 100 de TCA du lait emprésuré par la présure animale. Temps d'action $5 \mathrm{~h} \longrightarrow, 5 \mathrm{j} \longrightarrow-$.

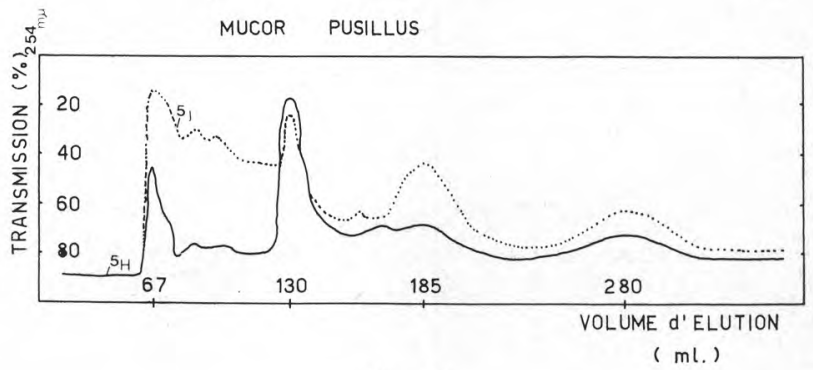

fig. 14

Chromatographie sur colonne de Séphadex $\mathrm{G}_{10}$ de l'extrait par 2 p. 100 de TCA du lait emprésuré par Mucor pusillus. Temps d'action : $5 \mathrm{~h} \longrightarrow, 5 \mathrm{j}-\longrightarrow$.

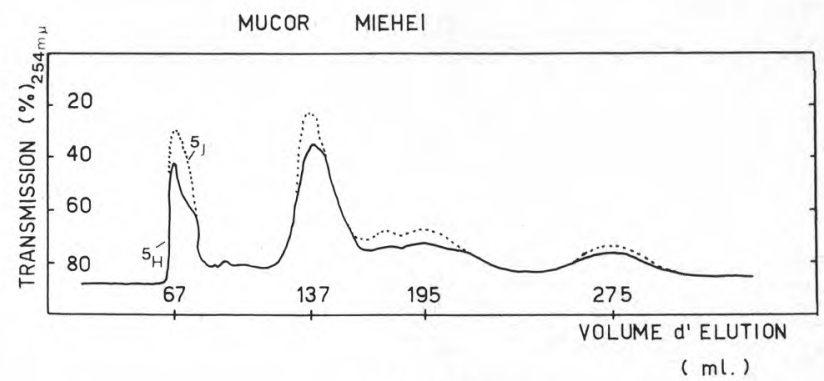

fig. 15

Chromatographie sur colonne de Séphadex $\mathrm{G}_{10}$ de l'extrait par 2 p. 100 de TCA du lait emprésuré par Mucor miehei. Temps d'action : $5 \mathrm{~h} \longrightarrow, 5 \mathrm{j}-\longrightarrow$. 


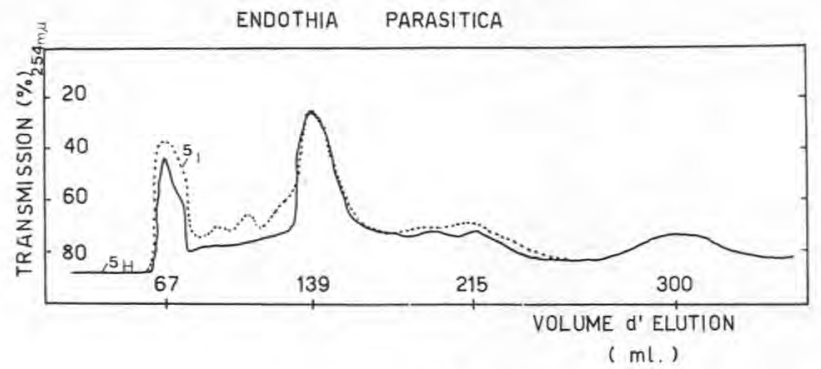

fig. 16

Chromatographie sur colonne de Séphadex $\mathrm{G}_{10}$ de l'extrait par 2 p. 100 de TCA du lait emprésuré par Endothia parasitica. Temps d'action : $5 \mathrm{~h} \longrightarrow, 5 \mathrm{j} \longrightarrow-$.

\section{III.2.2. Séparation des produits de la protéolyse sur Séphadex}

Afin de caractériser l'action protéolytique spécifique à chaque enzyme, nous avons séparé sur gel de Séphadex les peptides extraits $5 \mathrm{~h}$ et $5 \mathrm{j}$ après l'emprésurage ; le filtrat (TCA 2 p. 100) du lait nonemprésuré est considéré comme témoin (fig. 12). La séparation obtenue à partir de ce lait, fait apparaître trois pics principaux à des volumes de 70, 135 et $200 \mathrm{ml}$, correspondant à des peptides de dimensions de plus en plus petites. Le passage sur colonne des produits extraits $5 \mathrm{~h}$ après l'emprésurage est traduit dans les graphiques (fig. 13,15,16,17). On ne distingue pas entre ces enregistrements des différences fondamentales. Il faut cependant noter, dans tous les cas, le développement d'un épaulement très marqué au niveau du premier pic et l'augmentation des peptides élués à $135 \mathrm{ml}$ et plus particulièrement sous l'action de l'Emporase. Les peptides du témoin élués à $200 \mathrm{ml}$ ne se retrouvent plus dans les laits emprésurés; ils ont vraisemblablement subi la dégradation en unités de poids moléculaires inférieurs.

Les chromatographies des extraits des laits emprésurés pendant 5 j laissent apparaître des modifications importantes par rapport au témoin.

Présure animale (fig. 13).

Comparés aux résultats obtenus après $5 \mathrm{~h}$ d'emprésurage, on constate après $5 \mathrm{j}$ d'emprésurage que la concentration des peptides élués à $128 \mathrm{ml}$ diminue, mais il apparaît un pic ayant un volume d'élution de $150 \mathrm{ml}$. On note encore l'apparition de pics mal différenciés correspondant à des volumes d'élution de 95, 184 et $205 \mathrm{ml}$ et un glissement des produits élués à $270 \mathrm{ml}$ vers $285 \mathrm{ml}$. Ces déplacements de pics correspondent à un fractionnement plus poussé des peptides qui subissent ainsi un temps de rétention plus Iong.

Présure de Mucor pusillus (fig. 14). 
Il apparaît immédiatement que le substrat emprésuré par l'Emporase subit une protéolyse particulière tant par son intensité que par la nature des produits. On observe une augmentation considérable de l'absorption des substances éluées entre 65 et $95 \mathrm{ml}$, tandis que le pic situé à $130 \mathrm{ml}$ décroît sensiblement. Les peptides élués à $185 \mathrm{ml}$ augmentent fortement. La protéolyse du lait par cette présure se caractérise donc par une accumulation de peptides, gros et moyens.

Présure de Mucor miehei (fig. 15).

Le substrat traité par la Rennilase ne semble guère évoluer au cours de la période de $5 \mathrm{~h}$ à $5 \mathrm{j}$ qui suit l'emprésurage, tout au moins en ce qui concerne les peptides solubles en présence de 2 p. 100 de TCA. On observe cependant un accroissement de l'intensité des pics et l'apparition de peptides à $86 \mathrm{ml}, 163 \mathrm{ml}$ et $180 \mathrm{ml}$ d'élution. Cette chromatographie montre une protéolyse ordonnée et progressive du lait sous l'action de la Rennilase.

Présure d'Endothia parasitica (fig. 16).

Par rapport à l'emprésurage de $5 \mathrm{~h}$, l'extrait après $5 \mathrm{j}$ marque une évolution très sensible dans la zone des gros peptides élués entre 67 et $139 \mathrm{ml}$. Dans cette zone, on note le développement de deux nouveaux pics à 100 et $115 \mathrm{ml}$. Cette présure ne semble pas pousser la protéolyse au-delà des peptides élués à $215 \mathrm{ml}$.

\section{IV. - CONCLUSION}

Pour que la coagulation du lait par une présure soit reproductible, il est nécessaire de considérer simultanément la teneur en $\mathrm{Ca}^{++}$, la température, le $\mathrm{pH}$ et la force de l'enzyme et ce, en relation avec d'autres facteurs tels le pourcentage en $\mathrm{NaCl}$, la nature du substrat... Puisque ces facteurs sont difficilement dissociables, leur étude séparée ne peut avoir qu'une importance relative. Dès lors, il est normal que nos analyses diffèrent quelque peu des travaux cités dans la littérature $[3,7,11,15]$ dont les conclusions varient souvent.

L'évolution de la protéolyse, par contre, est plus significative puisque les facteurs précités sont considérés globalement. Le fait de suivre la protéolyse pendant $5 \mathrm{j}$ après l'emprésurage nous permet de compléter les différents travaux $[2,3,15,17]$ dans lesquels le phénomène a été analysé pendant les 2 premières heures. La production de peptides solubles en présence de 12 p. 100 de TCA est intense dès le début de la protéolyse des présures d'origine fongique, mais elle se stabilise par la suite. Les succédanés de la présure animale se différencient de cette dernière par une hydrolyse importante dès l'emprésurage et par les types de peptides libérés. L'enzymes extrait 
de Mucor pusillus se caractérise par une forte concentration de gros peptides élués entre 67 et $130 \mathrm{ml}$ pouvant expliquer le goût amer décelé dans certains fromages fabriqués avec cette enzyme [18]. La diminution du rendement signalé par Kikuchi [18] et Maubois [10] peut être due à une production importante de peptides solubles dans l'eau.

\section{Remerciements}

Nous remercions $M$. Akueni pour sà collaboration et les Firmes Pfizer, Novo Industries A/S et Dairyland food Laboratories Inc. pour les échantillons qu'ils nous ont fournis.

\section{Ré s u mé}

L'étude comparative de l'activité coagulante de la présure animale et de trois de ses succédanés extraits successivement de Mucor pusillus, de Mucor miehei et d'Endothia parasitica a montré que des vitesses de coagulation sont différentes lorsque la teneur en ions calcium, la température et le $\mathrm{pH}$ varient.

La protéolyse du lait écrémé par ces enzymes est spécifique pour chacune d'elles, et elle se caractérise par une protéolyse plus intense pour les succédanés de la présure animale et par une accumulation d'une classe de peptides chez Mucor pusillus et chez Endothia parasitica.

\section{S u m m a r y}

The comparative study of the milk clotting of rennet and of three of its substitutes extracted successively from Mucor pusillus, Mucor miehei and Endothia parasitica has shown that the rate of clotting is different when the calcium ions concentration, the temperature and the $\mathrm{pH}$ vary.

The proteolytic activity on skim milk with this enzymes is specific for each of them and it is characterized by a higher proteolytic activity for the rennet substitutes and by accumulating of one class of peptides for Mucor pusillus and Endothia parasitica.

Reçu pour publication en août 1973.

\section{Bibliographie}

[1] Alais (C.), Mocouot (G.), Nitschmann (Hs) et Zahler (P.) (1953). - Helv. Chim. Acta, 36, 1955. 
[2] Alais (C.) et NovaK (G.) (1968). - Le Lait, 477, 393.

[3] Alais (C.) et Lagrange (A.) (1972). - Le Lait, 517, 407.

[4] Behnke (V.) et Siewert (R.) (1969). - Milch. Stand., 11 (2), 66.

[5] Bolliger (O.) et Schilt (P.) (1969). - Separatabdruk aus der Schweizerischen Milchzeitung, Schaffhausen, 59.

[6] Edelsten (D.), Hamdy (A.) and El Kousy (L.) (1969). - Royal veterinary and agricultural university, Copenhagen, Denmark - Jearbook, 201.

[7] HaMdy (A.) und Edelsten (D.) (1970). - Milchwissenschaft, 25, 450.

[8] KieRMeIR (F.). - Rapport adressé à la firme Pfizer.

[9] LeNoIR (J.) (1963). - Le Lait, 43, 154.

[10] Maubois (J. L.) et Mocouot (G.) (1969). - Le Lait, 488, 497.

[11] Novo (1969). - Enzyme information, 22-127-2.

[12] Ramet (J. P.), Alais (C.) et Weber (F.) (1969). - Le Lait, 481-482, 40.

[13] Ramet (J. P.) et AlaIs (C.) (1972). - Le Lait, 519-520, 654.

[14] Stadhouders (J.) (1962). - Cong. Int. Lait, Copenhagen, B 353-361.

[15] Statens Fors $\varnothing$ gsmejerei, Hiller $\varnothing$ d Beretning (1969), N2, 179.

[16] Thonnasow (J.), Mrowetz (G.) und Schmanke (E.) (1970). - Milchwissenschaft, 4, 211.

[17] Vanderpoorten (R.) and Weckx, (M.) (1972). - Neth. Milk Dairy J., 26, 47.

[18] Suivant références 1, 12, 14, 27 de l'article de BeHNKe (V.) et col. (1969), Milch. Stand, 11 (2), 66. 